\title{
Políticas de inclusión: ¿educación obligatoria o derecho a la educación?
}

\author{
Luis Ernesto Behares* \\ Universidad de la República
}

Resumen Este artículo estudia, desde una perspectiva teórica y de análisis ideológico, la junción entre las políticas de inclusión, como paliativas de la exclusión, y la postulación de los derechos individuales, sobre todo en el ámbito de la educación. Se incluye un estudio sobre los orígenes y vaivenes de la noción de exclusión/inclusión, en sus vínculos con las ideologías neoliberales y con las posteriores interpretaciones "progresistas". La postulación contemporánea de derechos individuales, con sus características y trasfondo ideológico, se analiza con especial atención a los procesos de Argentina, Bolivia, Brasil, Chile, Paraguay y Uruguay. Las políticas de inclusión y de derechos muestran líneas paralelas, con junciones relativas y no estructurales, tanto en su formulación política como en su instrumentación. El vínculo entre ellas se hace notorio al definir la educación a partir de los derechos. Particularmente, el artículo profundiza el entramado de los conflictos conceptuales y operativos derivados del encuentro de las políticas más tradicionales de obligatoriedad de la educación básica, que es estatutaria en la mayoría de los países, con los intentos de definir la educación como un instrumento para asegurar el goce efectivo de los derechos consagrados internacionalmente, que se ha hecho normal en la legislación en materia de educación.

PALABRAS CLAVE: Inclusión; Derechos; Educación; Obligatoriedad. 


\title{
Policies of inclusion: compulsory education or the right to education?
}

\begin{abstract}
This article deals, from a theoretical perspective and via an ideological analysis, with the joining of policies of inclusion, as a palliative from exclusion, with the postulation of individual rights, especially in the field of education. A study on the origins and fluctuations of the notion of exclusion/inclusion, in their relationship with neo-liberal ideologies and its subsequent "progressive" interpretations is included. The contemporary proposal on individual rights, its features and ideological background, is analysed, paying special attention to the processes in Argentina, Bolivia, Brazil, Chile, Paraguay and Uruguay. Policies of inclusion and rights exhibit parallel lines, with intersections that are relative rather than structural, both in relation to their political formulation as well as to their implementation. Their relationships becomes notorious when education is defined in terms of rights. In particular, the article looks deeper into the composition of the conceptual and operative conflicts that derive from the encounter between the traditional policies on compulsory basic education, which is statutory in most countries, and the attempts at defining education as an instrument to ensure the enjoyment of internationally recognised rights that have become the norm in legislation on education.
\end{abstract}

KEYWORDS: Inclusion; Rights; Education; Compulsoriness.

\section{Políticas de Inclusão: educação obrigatória ou direito à educação?}

Resumo Esse artigo estuda, desde a perspectiva teórica e de análise ideológica, a junção entre as políticas de inclusão, como paliativas da exclusão, e a postulação dos direitos individuais, principalmente no âmbito da educação. Inclui-se um estudo sobre as origens e vaivéns da noção de exclusão/inclusão, em seus vínculos com as ideologias neoliberais e com as interpretações "progressistas" posteriores. A postulação contemporânea de direitos individuais, com suas características e fundos ideológicos, é analisada com atenção especial aos processos de Argentina, Bolívia, Brasil, Chile, Paraguai e Uruguai. As políticas de inclusão e as de direitos têm linhas paralelas, com junções relativas e não-estruturais, no que diz respeito à formulação política e às instrumentalizações. $O$ vínculo entre elas fica notório na definição da educação com base nos direitos. Em particular, o artigo aprofunda na malha dos conflitos conceptuais e operacionais derivados do encontro das políticas mais tradicionais de obrigatoriedade da educação básica, estatutária na maior parte dos países, com os intentos para definir à educação como um instrumento para assegurar o gozo efetivo dos direitos consagrados a nível internacional, já normal na legislação sobre educação.

PALAVRAS-CHAVE: Inclusão; Direitos; Educação; Obrigatoriedade. 


\section{Políticas de inclusión y políticas educativas}

Muchas propuestas y realizaciones contemporáneas en políticas educativas se vinculan con lo que se conoce como "políticas de inclusión", que adoptaron varias formas y permearon los sistemas educativos de la gran mayoría de los países del mundo. Se entiende corrientemente que están ligadas a los modelos de desarrollo de las sociedades y a las acciones tendientes a la justicia social mediante la promoción de los derechos de las poblaciones e individuos.

Los estudios sobre las políticas públicas enfocadas a los entramados educativos revelan la gran heterogeneidad de lo que se entendió por inclusión. Suelen enfocar preponderantemente los aspectos jurídicos, instrumentales y de formato pedagógico, pero la espesura de las cuestiones implicadas exige una indagación más cuidada acerca de sus sustentos teóricos e ideológicos, lo que será el objetivo de este trabajo. En especial analizaremos la postulación de la educación como derecho fundamental (polo de justicia) y como obligación de los estados y ciudadanos (polo político). La consideración de ambos polos y de las interacciones entre ellos se presenta, según nuestra hipótesis de trabajo, como tarea inherente y necesaria para el estudio ponderado de las políticas de inclusión.

\section{Orígenes y vaivenes de las políticas de inclusión}

Exclusión, como concepto operativo, tuvo origen en Francia en la década de 1980 e irrumpió en 1988 con el Revenu Minimum d'Insertion (RMI), cuya intención fue crear mecanismos para ampliar el acceso al trabajo de los ciudadanos desempleados en edad de trabajar (cfr. THÉVENET, 1989). Empero, se había formulado antes, en el contexto de la sociología y de las ciencias políticas académicas a partir del difundido libro de Lenoir (1974), Les exclus: un française sur dix, pieza del pensamiento teórico-ideológico del neoliberalismo político-económico. Como sostuvo Castel (1997), la sociedad francesa, y en gran medida la sociedad europea, resolvió históricamente la cuestión social pasando del tutelaje medioeval al contrato decimonónico y de este al "estatuto" de las políticas de salario en el siglo XX. El salario y el empleo son en ellas las claves definitorias de la ciudadanía plena. Lenoir (1974) ubicó a los "excluidos" en los grupos poblacionales que no encontraban su lugar en el nexo salarial y para los cuales el derecho pleno de ciudadanía estaba limitado.

La solución preconizada fue la promoción de los derechos de los individuos a través de programas de protección social en los marcos de la globalización y de la flexibilización laboral, como fue el caso del RMI. Se trataba de un principio de la sociología clásica: ya en 1895, Durkheim (2007) reconoció y dio preeminencia a la cohesión social, resultado, según su visión teórica, del establecimiento del lazo social (lien social). También señaló los problemas que se derivan de los lazos sociales débiles, por ausencia de vínculos de los ciudadanos con el estado-nación. Desde su punto de vista, la ciudadanía dependía de la consistencia de esos lazos. La exclusión se entendió como un derivado de la carencia de derechos, recursos y capacidades básicas de algunos ciudadanos para una participación social plena. Esta definición es opaca, al decir de Haan (2001, p. 28): "la exclusión social es un concepto teórico, un lente a través del cual se mira la realidad, y no la realidad misma"1. 
Didier (1996) distinguía tres paradigmas para la postulación de la noción de exclusión. El paradigma-Lenoir se refería a los individuos: "los excluidos son una categoría, o sea un conjunto de individuos que se asemejan en un rasgo y que en virtud de este merecen ser agrupados" (DIDIER, 1996, p. 7). La característica esencial de esta categoría es que "las personas que la constituyen son inadaptados" (p. 8), según el punto de vista lamarckiano de adaptación "activa a las circunstancias", que hace que los individuos menos aptos sean relegados. Si bien el texto de Lenoir (1974) no ponía el acento en las características personales psicológicas, partía de ellas para caracterizar el conjunto de los inadaptados. El "paradigma-Wrésinski" definía la exclusión a partir de la cultura o la civilización, sin remisión a las condiciones personales de los individuos, porque optaba por definir la cultura (sinónimo para él de "civilización") como "la instancia más global por la cual se puede definir la sociedad"(DIDIER, 1996: p. 9). La exclusión era para Wrésinski (1984) el resultado de privar a los sujetos del goce de los bienes culturales y civilizatorios, como la familia, la escuela, la iglesia y otros, pero sobre todo la ley y los derechos: ser excluido es no ser alcanzado. El paradigma del Institut National de la Statistique et des Études Économiques (INSEE) definía la exclusión a partir del mercado: el conjunto de procesos que impiden en forma durable que las personas puedan intervenir en uno o diversos "mercados", sean de trabajo o de otros tipos (culturales, de conocimiento, de inserción religiosa o deportiva, etc.) $)^{2}$. Didier (1996: p. 13) concluyó que para la tradición francesa la exclusión es un constructo que agrupa esos tres modelos incompatibles, pero que aun así se entremezclaron en el discurso sociopolítico.

La noción de exclusión se alimentó en el entorno europeo de la década de 1990 de las ideologías neoliberales, del pensamiento de la globalización, de las libertades de mercado y de la responsabilización individual frente a la inserción en la vida social. La inclusión fue su antídoto operativo y consistía en revertir las condiciones que limitaban la responsabilidad social de los individuos. Utilizaba para ello la legislación de derechos y obligaciones, las reestructuras educativas, los programas de formación para el empleo y las políticas dirigidas a individuos en situación de exclusión. Exclusión se opuso al concepto más tradicional de pobreza, en el que se cargaban las tintas en la distribución de los bienes materiales, al de clase social marxista, que establecía la determinación de los individuos por su lugar en la estructura trabajo-capital, o al concepto de marginación, que era más tradicional en los Estados Unidos.

Fuera de Europa, el concepto de pobreza recuperó o mantuvo la jerarquía que debió ceder al de exclusión. En la Unión Europea, se sigue hablando de exclusión, pero en los énfasis que se ponen predomina la noción de pobreza. De hecho, el programa de la Unión Europea se llama Plataforma Europea contra la Pobreza (UE, 2010), y en su contenido se muestra ese retorno, que ya estaba anunciado en documentos anteriores (por ejemplo en UE, 2003, p. 9). Para Room (1995, p. 3) los vaivenes del Consejo Europeo en la materia pueden explicarse, siguiendo parámetros de Realpolitik, por "la hostilidad de ciertos gobiernos al lenguaje de la pobreza y el entusiasmo de otros por usar el lenguaje de la exclusión social", que él mismo no hesita en considerar como vaivenes semánticos superficiales. Por su parte, Silver y Miller (2003, p. 7) entienden que la Unión Europea explicó la exclusión como la inhabilidad de las personas de ejercer los "derechos sociales ciudadanos" para lograr el estándar básico de vida y como 
barrera a la "participación" en las oportunidades sociales y ocupacionales de la sociedad, pero que en la mayoría de los países que la integraban (sobre todo en Gran Bretaña) se siguió interpretando que "exclusión" no era más que un sinónimo de "pobreza".

Con el concepto de exclusión (y su positivo de políticas públicas: la inclusión) hubo también un intento en el contexto neoliberal europeo de trasladar los problemas estructurales desde la pobreza y las dificultades de integración al sistema de mercado hacia las diferencias o diversidades sociales y culturales. Lo ha anotado Camilloni (2008, p. 5), al decir que "de la pobreza como causa y producto de la exclusión se pasa a la atribución de la diversidad como causa de la exclusión”. Ad libitum, la amplitud a la hora de valorar las causas de la exclusión implicó el enfoque múltiple y acumulativo, Así, se pudo llegar a definir como excluidos a una parte considerable de la sociedad. Lenoir (1974) había establecido una lista de causales de la exclusión, que Sen (2000, p. 1) completa: discapacitados físicos y mentales, suicidas, inválidos por edad avanzada, niños abusados, drogadictos, delincuentes, madres solteras, inadaptados urbanos, marginales, personas asociales, y algunos otros. Como se observa, la lista tiene el carácter de una colección abierta, en la cual no siempre es evidente cuál es el rasgo que la organiza. Por su parte, Camilloni (2008, p. 5) agrega que la indefinición del término permitió incorporar en su alcance a los pobladores de zonas rurales remotas, los grupos aborígenes, las minorías étnicas, lingüísticas y religiosas, las personas con necesidades especiales, los grupos nómadas, los que padecen enfermedades contagiosas y, en términos generales, a todos aquellos que "son diferenciados de los demás y sobre los que pesa, por esta razón, un estigma social”.

Las dinámicas de la llamada exclusión se originan en las clases dominantes o directivas en un intento para proteger valores y normas establecidas en la tradición. Las leyes son, según Elías (1997), las que aseguran esos valores y normas. Quienes satisfagan estas normas y funcionen adecuada o "normalmente" en los sistemas sociales regidos por las leyes establecidas, se ubican en el polo positivo, quienes no lo logren o no deseen lograrlo se situarán en el polo negativo. Las enumeraciones de situaciones que mencionamos evidencian que las categorizaciones están marcadas por una amplia diversidad de criterios, que evocan en su justificación a la hermenéutica que introdujo Foucault (2006) respecto a "los anormales". Al decir de Touraine (1997, p. 48), la "noción de exclusión no define intrínsecamente quiénes son los excluidos y de qué lo son”, porque existe una cierta tendencia a identificar diversidades demasiado heterogéneas con la condición de excluido, pasando por alto la importancia de la posición de los individuos en la estructura social. Una crítica marxista del concepto de exclusión debería, obviamente, partir de esta anotación ${ }^{3}$.

Al desmontar lo que la noción de exclusión parece abarcar, es posible distinguir varias dimensiones que están presentes en su entramado, pero todas ellas exigen establecer cuál sería la condición "normal” de la que se apartan. García Roca (1998), reconoció, para el contexto español, tres: la estructural o económica (recursos materiales para la subsistencia); la contextual o social (disociación de los vínculos sociales) y la subjetiva o personal (responsabilidades individuales). Con certeza, parecen insuficientes y regidas por un ideal de sujeto social restricto al miembro de la burguesía culturalmente integrada. Fuera de las sociedades europeas, aunque también en ellas, las diversidades de clase, étnicas, religiosas y lingüísticas, por ejemplo, suelen ser determinantes. 


\section{Políticas de inclusión en Argentina, Brasil, Bolivia, Chile, Paraguay y Uruguay}

Al ser introducida en la década de 1990 en estos seis países, la noción de inclusión sufrió profundas modificaciones, en un proceso que podríamos calificar de asaz confuso. La pluralidad de significaciones que bordeaban el término "inclusión" no obstaron para que haya circulado en forma insistente en las políticas públicas y que haya ocupado un espacio de dimensiones inusitadas en la bibliografía académica, sobre todo en el ámbito de las políticas sociales, educativas y dirigidas a la niñez.

Esquemáticamente, hubo dos períodos bastante fáciles de diferenciar. E1 primero abarcó, aproximadamente, entre 1990 y 2005, en el marco de las políticas públicas originadas en los gobiernos explícita y desenfadadamente afines a la ideología neoliberal; el segundo se inició en el entorno de 2005, con el advenimiento de gobiernos con tendencias político-ideológicas de naturaleza "progresista", aunque no exentas de continuidades ideológicas con las anteriores.

En el primero de estos períodos se hicieron ensayos directamente orientados por los parámetros antes descritos para Europa, bajo la égida de diversos organismos internacionales. Los gobiernos de este período fueron en dirección a "reformas socioeconómicas de orientación al mercado" (MIDAGLIA; CASTILLO; FUENTES, 2010, p. 123), abarcaron diversos dominios de las políticas públicas y se dirigieron en particular a los sectores considerados como excluidos del mercado. ${ }^{4}$

En el segundo período, la noción de exclusión/inclusión fue sufriendo importantes resignificaciones ideológicas, a pesar de que se conservara gran parte de la terminología original. Los nuevos valores introducidos en estas redes de significaciones pasaron a coexistir con otros que venían de las políticas neoliberales. Encontramos dos direcciones definitorias: el combate a la pobreza y a la privación extrema ("miseria", "emergencia socio-económica"), que insumió muchos esfuerzos, con diferentes resultados en cada uno de los países, y políticas públicas de regulación del empleo, sobre todo para el sector considerado "no-calificado". Las estrategias inclusivas tuvieron un énfasis marcado en la atención a la pobreza, en un marco de referencia asociado a la idea de desarrollo con distribución más o menos inmediata o mejorada de los beneficios y los ingresos. En cada uno de los países se crearon ministerios u oficinas de rango semejante para atender estas políticas focalizadas ${ }^{5}$. Cada uno de estos organismos de gobierno generó programas y planes ligados a la inclusión, centrados en la atención a la pobreza ${ }^{6}$.

Hubo, además, avances en las políticas públicas referidas a grupos sociales considerados minoritarios (por género, ocupación, opción sexual, edad, discapacidades y "raza", entre otros), que no tienen conceptualmente relación necesaria con la privación económica y que fueron más fuertes en algunos países. Se trató de otras políticas públicas, pero que en gran medida se instrumentaron por separado. Sin embargo, el término inclusión se utilizó también para estos casos. Los gobiernos posteriores a 2005 incluyeron incipientemente en su agenda de inclusión las situaciones de los grupos étnicos originarios, las comunidades lingüísticas asociadas con la migración y las comunidades sordas, con resultados disímiles, cuyo mayor impacto puede haber sido 
en educación. Sin embargo, los tratamientos que dieron a cada una de ellas fueron claramente asimilacionistas, más en unos países que en otros, y contemplaron bastante pasivamente la discriminación estructural que reside en el fondo de estas situaciones (BEHARES, 2014, 2015). En este aspecto, países como Argentina, Brasil o Chile no han logrado avanzar definidamente en políticas de reconocimiento de su notoria diversidad. El caso brasileño es un ejemplo de esta dificultad, si se observan los escasos avances en la materia desde la Constitución de 1988 (BRASIL, 1988). Puede considerarse excepción al Estado Plurinacional de Bolivia, sancionado como tal en la Constitución de 2009 (BOLIVIA, 2009), aún en proceso de instrumentación.

\section{Políticas de inclusión y agenda de derechos}

Cuando los Derechos Humanos, postulados desde el derecho internacional ${ }^{7}$, comenzaron a consagrarse como estatutos positivos y se insertaron en los marcos jurídicos nacionales a partir de la década de 1990, lo hicieron con referencia a las políticas de inclusión. De hecho, los documentos generados en el contexto europeo en términos de derechos económicos, sociales y culturales (por ejemplo CdE, 1995) se asociaron perfectamente con las lógicas y los sentidos de la inclusión que analizamos más arriba, si bien también tuvieron relación intrínseca con otros órdenes de políticas, tendientes a la integración europea, al rescate cultural y a regularizar reivindicaciones nacionalistas de las más variadas direcciones ideológicas.

La puesta en práctica de los derechos ha seguido una línea de desarrollo paralela a la inclusión. Las intersecciones más frecuentes estuvieron asociadas con la pobreza o con las dificultades de integración al mercado de trabajo. Cuando ambas líneas se encuentran, la junción de las políticas de derechos con las de inclusión es clara; en cambio no hay verdaderas junciones en el resto de las situaciones.

Tanto las políticas de inclusión como las de derechos fueron justificadas y establecidas con atribución a los individuos singulares y no a los intereses de grupos, sean de clase, sociales o culturales. Los estados han sido muy cautos en no transgredir las barreras del individualismo al atribuir derechos ligados a lo étnico, cultural o a las tendencias nacionalistas regionales. Un estado es una unidad estable y tiende siempre a la aprehensión frente a todo aquello que pueda debilitar la unidad o abrir brechas en la diversidad constitutiva imaginariamente domeñada. Los documentos internacionales han tendido siempre a minimizar los derechos colectivos y han puesto entre comillas aquellos que puedan ir más allá de los derechos individuales. Incluso en los documentos referidos puntualmente a la diversidad étnica (ejemplo: Declaración de los Derechos de los Pueblos Indígenas, ONU, 2008) la tendencia aprehensiva está muy presente. El asimilacionismo homogeneizante ha estado siempre presente en el conjunto documental, al postularse que la tarea inclusiva consiste en el aseguramiento de la equidad de condiciones en el punto de partida, para llegar finalmente a la condición plena de ciudadanía, sin tomar en cuenta que las comunidades son refractarias a perder su propio lugar de poder contrahegemónico.

Los derechos positivos suponen obligaciones, no sólo para aquellos que deben asegurarlos y protegerlos (los estados o las agrupaciones de estados), sino también 
para aquellos que son sus titulares. La relación derechos-obligaciones constituye una unidad inseparable, si se la concibe como el articulador de la ciudadanía, que está en el centro de la justificación de las políticas de inclusión. El ciudadano es el titular de derechos, si bien en la tradición liberal iniciada en 1789 por Francia (1990) y en su desarrollo histórico posterior se introdujo también el raciocinio naturalista, que coexiste intrincadamente con la tradición positivista desde entonces. Tanto las políticas de inclusión como las de derechos hacen hincapié en el término "social", llevando la noción de ciudadano a una dimensión más avanzada y menos formal, al suponerlo también como parte de una comunidad o sociedad, que sólo puede concebirse como política, según la caracterización de Cheresky (2006): el ciudadano es un conjunto de atributos legales y a la vez un miembro de la comunidad política. Podemos, considerar politico y social como sinónimos; en cierta forma la tradición de políticas de inclusión social lo hace, pero también es posible oponerlos con significados diferentes en trámites discursivos disímiles.

\section{Políticas de inclusión en el campo educativo: derechos y obligaciones}

La obligatoriedad de la educación es producto del ideal moderno de Estado y de su vínculo político con la sociedad, en el marco del desarrollo capitalista. Este fait accompli se formalizó durante el siglo XIX, aunque existan antecedentes (la reforma luterana y la contrarreforma jesuítica, por ejemplo). Los modelos que posibilitaron su universalización deben buscarse en el iluminismo, desde el Aufklärung alemán ("modelo prusiano", implantado en 1812), en el empuje napoleónico para crear desde 1806 una universidad estatal que dominara toda forma de educación, en el transporte de estos enfoques a los Estados Unidos por Horace Mann entre 1842 y 1876, en la aprobación en Francia (Tercera República) de las Leyes de Jules Ferry entre 1878 y 1887, en la obra político-pedagógica de los rioplatenses Sarmiento $(1849,1866)$ y Varela $(1874$, 1964) y en la adopción posterior de los parámetros fundamentales de la obligatoriedad por la denominada "escuela nueva" (DEWEY, 1916) ${ }^{8}$.

En el sur de Sudamérica, la obligatoriedad de la educación es actualmente principio establecido y poco discutido. Alcanza a los individuos comprendidos idealmente entre los 4 y los 18 años, con variaciones en cada país ${ }^{9}$. Argentina y Uruguay la implantaron para la educación primaria en el siglo XIX (URUGUAY, 1878; ARGENTINA, 1884), Brasil lo hizo en 1934 a nivel federal, librando su aplicación a decisiones municipales (BRASIL, 2001), Chile estableció la primaria obligatoria en 1920 (CHILE, 1921), Paraguay manifestó la aspiración en 1870 (PARAGUAY, 1870), pero no logró implantarla hasta 1998 (PARAGUAY, 1998) y en Bolivia, que ya había manifestado el valor de la medida en 1851 (BOLIVIA, 1851), debió esperar hasta 1994 (BOLIVIA, 1994). La obligatoriedad estuvo ligada para Argentina y Uruguay, y en menor medida para Chile, a la estabilización positivista de las relaciones entre el Estado y la sociedad, a la homogeneización de la población y al ideal liberal de democracia republicana socializante ${ }^{10}$, de lo cual se derivan los principios subsidiarios de gratuidad, libertad de oferta educativa, universalización y, para algunos de estos países, de laicidad. Bolivia, Brasil y Paraguay no llegaron a estos extremos tan fácilmente y 
la obligatoriedad tuvo más bien en ellos sentido asistencialista para las condiciones sociales deficitarias de diversas poblaciones.

La obligatoriedad fue un procedimiento de inclusión avant la lettre, caracterizado por la determinación coercitiva, en la cual los parámetros intrínsecos de las políticas posteriores de "inclusión” ya estaban presentes. La obligatoriedad es un requisito político imprescindible, porque está ligada a las relaciones del Estado con los miembros de la sociedad o "pacto de ciudadanía". Educarse es obligatorio porque es uno de los modos de obtener la ciudadanía plena, responsable y comprometida, mediante el disciplinamiento productivo. Es obligatoria para el Estado, que debe instrumentar servicios, generalmente gratuitos a su cargo, para los padres de los sujetos tutelados en la edad establecida, a los cuales el Estado debe imponer el cumplimiento, y para los niños-adolescentes, que deben participar de las actividades educativas.

Se entiende que las políticas de inclusión se caracterizan como catalizadoras de derechos y no como impositoras de obligaciones. A texto expreso así lo han establecido los documentos más generales y preceptivos en la materia, las leyes de educación y otros documentos vinculados ${ }^{11}$. Sin embargo, la tradición liberal-republicana exige para su propia constitución la obligatoriedad de la educación, entre otras obligaciones asociadas al pacto político. De esta forma, nos encontramos con la coexistencia de la obligatoriedad y de los derechos a la educación en la legislación educacional ${ }^{12}$. Desde el punto de vista jurídico, obligaciones y derechos son conceptos operacionales diferentes, aunque en cierto nivel se presenten indiferenciados en las Leyes de Educación. Es posible suponer cierta incongruencia técnico- jurídica al definir la relación de los ciudadanos con la educación en términos de obligación y de derechos a un mismo tiempo.

E1 Estado es necesariamente el garante de un sistema educativo inclusivo que haga posible el goce universal del derecho a la educación. El derecho individual a la educación tiene como contrapartida la obligatoriedad para el Estado de proveer los medios para esto, con inherencia absoluta, más allá de que las acciones de los gobiernos, que no son el Estado, puedan concurrir mejor o peor a lograrlo. La cuestión se pone, en cambio, para padres y niños-adolescentes de una manera más compleja.

Los padres y tutores son, según la preceptiva internacional más reconoci$\mathrm{da}^{13}$, los titulares de los derechos a educar a sus hijos. De su derecho se desprende, de jure, la obligación del Estado para las prestaciones correspondientes. Sin embargo, se los presenta también como titulares imputables de una obligación, expresada a la vez como la de educar a sus hijos y la de inscribirlos y mantenerlos dentro del sistema de enseñanza (o instrucción) que el Estado debe proveer. Este sistema, originariamente enfocado a la enseñanza, ha ido derivando con el tiempo a arrogarse la función educativa, por complejos procesos de consolidación de los estados-naciones-sociedades. En este contexto surgen como preguntas: ¿La obligación del estado se refiere a la enseñanza o también a la educación? ¿El derecho de los padres a educar es transferido o conjugado con una inadmisible titularidad de derechos al Estado? Estos problemas se manifiestan en la exterioridad de los padres respecto a las organizaciones y diseños de los sistemas educativos, a los modos de enseñar, a los curricula, a los valores a ser 
transmitidos y a todo aquello que forma parte del modelo educativo contemporáneo, problemas que parecen existir en forma amortiguada para los padres de la clase media urbana, pero que son altamente conflictivos para aquellos que son miembros de grupos marcados por la diversidad económica, social, cultural, étnica, religiosa o lingüística.

Los niños-adolescentes, beneficiarios de su derecho a educarse, bajo la responsabilidad de sus padres y del Estado, están obligados a integrar los sistemas educativos, tanto por su asistencia a las actividades que este ofrece como por el aprovechamiento de sus componentes. Sabemos, no obstante, que estos goces obligatorios de su derecho establecen conflictos de variada naturaleza. Sobre todo en la adolescencia, cuando la obligatoriedad se proyectó más recientemente a estas edades, se han observado crisis de inadaptación de la oferta a los intereses de los beneficiarios del derecho y pérdida de los sentidos de los aprendizajes, generadora de frustración y evasión. Podrían considerarse que estos fenómenos son coyunturales y que dependen de la habilidad de los gobiernos para solucionarlos, pero tienen una dimensión estructural en el encuentro de derechos y obligaciones conjugados.

Cabe preguntarse si las políticas de inclusión educativa logran articular lo político, inherente a los diseños económico-sociales en las sociedades capitalistas, en donde se inscriben las obligatoriedades, con los reconocimientos de justicia, cerne de los derechos individuales.

\section{Referencias}

ARCHER, M. Social Origins of Educational Systems. Londres: Sage Publications. 1979.

ARGENTINA. Ley No 1420 de Educación Común. 8 de Julio de 1884. Disponible en: http:// www.bnm.mcye.gov.ar/demo2/documen/leyes/ley1420/indice.htm (consultado 15/02/18)

ARGENTINA. Constitución de la Nación Argentina. Buenos Aires: Sur. 1994.

ARGENTINA. Ley n $\mathbf{n}^{\circ}$ 26.206. Ley de educación nacional. 2006. Disponible en: www.me.gov. ar (consultado 15/02/18)

ATIENZA, M. Marx y los derechos humanos. Lima: Palestra. 2008.

BEHARES, L. E. Opciones educativas culturalmente sensibles a la diversidad y la implementación de los derechos lingüísticos. Educação (Santa Maria), v. 39, n. 2, pp. 265-276, maio/ago. 2014.

BEHARES, L. E. Políticas lingüísticas, derechos lingüísticos y políticas de inclusión social. Análisis de sus interacciones y de sus especificidades. In: REGUERA, A. (Comp.) VII Encuentro Internacional de Investigadores de Políticas Lingüísticas. Córdoba: Universidad Nacional de Córdoba-Asociación de Universidades Grupo Montevideo, pp. 59-79. 2015.

BEHARES, L. E. La centralidad del cuerpo en la integridad individual: los derechos y la educación. Conferencia pronunciada en el I Coloquio Estudios sobre la Educación del Cuerpo. Instituto Superior de Educación Física, Universidad de la República, 17 de Mayo de 2018 (inédito).

BOLIVIA. Constitución política de 1851, 21 de septiembre de 1851. Disponible en: <https:// www.lexivox.org/norms/BO-CPE-18510921.xhtml>. (consultado 03/03/18).

BOLIVIA. Ley 1565 - Reforma educativa de 1994. Disponible en: <http://e-ducacionboliviana. blogspot.com/2008/05/ley-1565-reforma-educativa.html>. (consultado 03/03/18). 
BOLIVIA. Constitución Política del Estado (CPE), de 2009. Disponible en: http://bolivia. infoleyes.com/shownorm.php?id=469. (consultado: 05/05/15).

BOLIVIA. Ley de la Educación “Avelino Siñani-Elizardo Pérez”. No 70, de 2010. Disponible en: http://www.filosofia.org/mfa/bo2010.htm (consultado 03/03/18).

BOURDIEU, P. Poder, Derecho y Clases Sociales. Bilbao: Desclée de Brouwer, 2000.

BRASIL. Constituições Brasileiras: 1934. vol. III completo. Brasília: Senado Federal e Ministério da Ciência e Tecnologia, Centro de Estudos Estratégicos. 2001.

BRASIL. Lei no 9.394, de 1996 (com modificações posteriores). Disponible en: http://www. planalto.gov.br/ccivil_03/Leis/L9394.htm. (consultado 12/01/18).

BRASIL. Constituição da República Federativa do Brasil. Brasília: Ministério da Educação. 1988.

CAMILLONI, A. W. de El concepto de inclusión educativa: definición y redefiniciones. Políticas Educativas, v. 2, n. 1, p. 1-12.1998.

CASTEL, R. Las metamorfosis de la cuestión social. Una crónica del salariado. Buenos Aires: Paidós. 1997.

CASTIGLIONI, R. The Politics of Social Policy change in Chile and Uruguay. Retrenchment versus maintenance, 1973-1998. New York y London: Routledge. 2005.

CdE - CONSEJO DE EUROPA. Text of the Framework Convention for the Protection of National Minorities and Explanatory report for the Protection of National Minories. Página del Consejo de Europa, European Treaty Series - No. 157 (1995) Disponible en: http:// www.coe.int/en/web/conventions/full-list/-/conventions/rms/090000168007cdac (consultado 21/09715).

CHERESKY, I. (Comp.) Ciudadanía, sociedad civil y participación política. Buenos Aires: Miño y Dávila Editores. 2006.

CHILE. Ley No 3,654 de 1921 - Sobre Educación Primaria Obligatoria. Santiago de Chile: Imprenta Lagunas \& Co. 1921.

CHILE. Ley 20.370, General de Educación de 2009, con modificaciones de 2010. Disponible en: https://www.leychile.cl/N?i=1006043\&f=2009-09-12\&p= (consultado 15/09/17).

CHILE. Constitución Política de la República. 2005. Disponible en www.oas.org/dil/esp/ Constitucion_Chile.pdf (consultado: 05/01/18). Con las enmiendas posteriores. 2010.

DEWEY, John. Democracy and education. An introduction to philosophy of education. New York: Macmillan. 1916.

DIDIER, E. De l' “exclusion” à l'exclusion. Politix, vol. 9, n’34, pp. 5-27. 1996.

DURKHEIM, E. Les règles de la méthode sociologique. Paris: Presses universitaires de France. 2007.

ELIAS, N. Les logiques de l'éxclusion. Paris: Fayard. 1997.

FOUCAULT, M. Los Anormales. México: Fondo de Cultura Económica. 2006.

FRANCIA. Déclaration des droits de l'homme et du citoyen. In Colliard, C-A. (Comp.) La déclaration des droits de l'homme et du citoyen de 1789. Paris: La Documentation Française, 1990, pp,. 15-19.

GARCÍA ROCA, J. Exclusión social y contracultura de la solidaridad. Prácticas, discursos y narraciones. Madrid: Editorial HOAC. 1998.

GIMENO SACRISTÁN, J. La educación obligatoria: su sentido educativo y social. Madrid: Morata. 2000. 
HAAN, A. de. Social Exclusion: enriching the understanding of deprivation. Deutsche Stiftung für internationale Entwicklung (DSE), Villa Borsig Workshop Series. Berlin. 2001. Disponible en: http://www. dse. de/ef/poverty/dehaan. Htm (consultado 20/04/18).

ILLICH, I. La sociedad desescolarizada. México: Joaquín Morata. 1985.

JEMIO, L. C. Reformas, políticas sociales y equidad en Bolivia. La Paz: Serie Reformas Económicas, No 38, Full. 1999.

LENOIR, R. Les exclus: Un Française sur dix. París: Editions du Seuil. 1974.

MARX, K. Sobre la cuestión judía. In: MARX. K. Escritos de Juventud. México: Fondo de Cultura Económica, pp. 461-490.1987.

MIDAGLIA, C.; CASTILLO, M. y G. FUENTES E1 Significado Político de los Ministerios Sociales en Argentina, Chile y Uruguay. Estado, Gobierno, Gestión Pública. Revista Chilena de Administración Pública, No15-16 (2010), pp. 123-154.

ONU- ORGANIZACIÓN DE LAS NACIONES UNIDAS. Declaración Universal de los Derechos Humanos. 1948. Disponible en: <www.un.org/es/documents/udhr>. (consultada 20/01/13).

ONU- ORGANIZACIÓN DE LAS NACIONES UNIDAS. Pacto Internacional de Derechos Civiles y Políticos. Disponible en: www2.ohchr.org/spanish/law/ccpr.htm (consultada 20/01/13). 1966a.

ONU- ORGANIZACIÓN DE LAS NACIONES UNIDAS. Pacto Internacional de Derechos Económicos, Sociales y Culturales. Disponible en: http://www.ohchr.org/SP/ProfessionalInterest/Pages/CESCR.aspx (consultado 20/01/13). 1966b.

ONU- ORGANIZACIÓN DE LAS NACIONES UNIDAS. Convención sobre los Derechos del Niño. Disponible en: <www.unicef.org/.../spanish/7.-Convencionsobrelosderechos. pdf>. (consultada 20/01/13). 1989.

ONU- ORGANIZACIÓN DE LAS NACIONES UNIDAS. Convención sobre los derechos de las personas con discapacidad. Disponible en: <www.un.org/esa/socdev/enable/documents/tccconvs.pdf>. (consultada 20/01/13). 2006.

ONU- ORGANIZACIÓN DE LAS NACIONES UNIDAS. Declaración de las Naciones Unidas sobre los derechos de los pueblos indígenas. New York: Naciones Unidas. 2008

PARAGUAY. Constitución de la República del Paraguay de 1870. Disponible en: <http:// www.bacn.gov.py/archivos-historicos/2305/constitucion-nacional-de-la-republica-del-paraguay-1870>. (consultado 21/04/18).1870.

PARAGUAY. Constitución de la República de Paraguay, 1992. Disponible en: www.wipo.int/ edocs/lexdocs/laws/es/py/py013es.pdf (consultado: 05/01/18).

PARAGUAY Ley N 1.264 General de Educación, de 1998. Disponible en: http://www.oei.es/ historico/quipu/paraguay/ (consultado 21/04/18). 1998.

PENDLE, G. Uruguay. Londres: Oxford University Press. 1963.

REAL DE AZÚA, C. El impulso y su freno. Montevideo: Editorial Banda Oriental. 1964.

REPETTO, F. y G. ALONSO. La economía política de la política social argentina: una mirada desde la desregulación y la descentralización. Serie Políticas Sociales N97. Buenos aires: CEPAL. 2004.

ROJAS VILLAGRÁN, J. (Coord.) Neoliberalismo en América Latina. Crisis, tendencias y alternativas. Asunción: CLACSO. 2015.

ROOM, G. Poverty and social exclusion: the new European agenda for policy and research. In ROOM, G. (ed.) Beyond the threshold. The measurement and analysis of social exclusion. Bristol: Policy Press. 1995. 
SARMIENTO, D. F. De la educación Popular. Santiago de Chile: Imprenta de Julio Belin i Co. 1849 .

SARMIENTO, D. F. Las escuelas: base de la prosperidad i la República en estados Unidos. Informe al Ministro de Instrucción Pública de la República Argentina. New York: sin editora. 1866.

SEN, A. Social Exclusion: Concept, Application, and Scrutiny. Social Development Papers 1. Manila: Office of Environment and Social Development, Asian Development Bank. 2000.

SILVER, H y S. M. MILLER Social Exclusion. The European Approach to Social Disadvantage. Indicators, vol. 2, 2, full. 2003.

TAYLOR GATTO, J. The underground history of American Education. Oxford: Oxford Village Press. 2003.

THÉVENET, A. R.M.I. Théorie et pratique. Paris: Bayard. 1989.

TOURAINE, A. ¿Podremos vivir juntos? Iguales y diferentes. Madrid, PPC Editorial. 1997.

UE - UNIÓN EUROPEA. Informe conjunto sobre la inclusión social en el que se resumen los resultados del examen de los planes nacionales de acción en favor de la inclusión social (2003-2005). Bruselas: Comisión Europea. 2003.

UE - UNIÓN EUROPEA. Combating poverty and social exclusion. A statistical portrait of the European Union 2010. Luxembourg: Publications Office of the European Union. 2010.

UNESCO- ORGANIZACIÓN DE LAS NACIONES UNIDAS PARA LA EDUCACIÓN, LA CIENCIA Y LA CULTURA. Convención de la UNESCO relativa a la recomendación sobre la lucha contra las discriminaciones en la esfera de la enseñanza. Disponible en: <portal.unesco.org/es/ev.php-URL_ID=12949\&URL_DO=DO_TOPIC\&...>. (consultada 20/01/13). 1960.

URUGUAY. Instrucción Pública. Su Reglamentación Administrativa, del 24 de Agosto de 1877. En: ALONSO CRIADO, Matías (Comp.) Colección Legislativa de la República Oriental del Uruguay. Montevideo: Imprenta Rural, Tomo IV: 632-646. 1878.

URUGUAY. Constitución de la República Oriental del Uruguay. Montevideo: Poder Legislativo. Texto de 1967, con las modificaciones posteriores. 2004

URUGUAY. Ley general de educación. Ley No 18.437. Montevideo: Dirección Nacional de Impresiones y Publicaciones Oficiales. 2008.

VANGER, M. José Batlle y Ordóñez: the creator of his times. Cambridge: Harvard University Press. 1963.

VARELA, J. P. La Educación del Pueblo. Montevideo: Tipografía de "La Democracia”. 2 Tomos. 1874 .

VARELA, J. P. La Legislación Escolar. Montevideo: Biblioteca Artigas. 1964.

VILMAR, F. Reformas institucionales y coordinación gubernamental en la política de protección social de Brasil. Buenos Aires: Serie Políticas Sociales No 64, CEPAL. 2003.

WRÉSINSKI, J. Heureux vous les pauvres. Paris: Cana. 1984.

ZUM FELDE, A. Evolución histórica del Uruguay: esquema de su sociología. Montevideo: M. García. 1945. 


\section{Luis Ernesto Behares}

\section{Notas}

${ }^{1}$ En este caso, como en todas las citas cuyas referencias están en lengua extranjera, fueron traducidas por nosotros.

${ }^{2}$ Algunos sentidos dados en el campo sociológico al término "capital cultural" (BOURDIEU, 2000) se inscribe en este marco de referencia.

${ }^{3}$ Desde el texto de 1843 de Marx (1987) y en el análisis de Atienza (2008).

${ }^{4}$ Consultar, para Bolivia a Jemio (1999), para Argentina a Repetto y Alonso (2004), para Chile y Uruguay a Castiglioni (2005) y para Brasil a Vilmar (2003). Aporta al conjunto de América Latina el volumen compilado por Rojas Villagrán (2015).

${ }^{5}$ Argentina: Ministerio de Desarrollo Social (1999); Brasil: Ministério de Desenvolvimento Social e Combate à Fome (2004); Chile: Ministerio de Desarrollo Social (2011); Bolivia: Ministerio de Desarrollo Social y Tierras, Ministerio de Desarrollo Productivo y Economía Plural, Ministerio de Planificación del Desarrollo (creados durante los últimos 20 años); Paraguay: Secretaría de Acción Social (2005); Uruguay: Ministerio de Desarrollo Social (2005).

${ }^{6}$ Brasil: Fome Zero, Borsa Família, Fundo Nacional de Assistência Social; Bolivia: diversos planes bienales; Chile: Chile Solidario y Chile cuenta contigo; Paraguay: Estrategia Nacional de Lucha Contra la Pobreza; Uruguay: Plan de Asistencia Nacional a la Emergencia Social, Ingreso Ciudadano, Trabajo por Uruguay, Plan de Equidad. Remitimos a Midaglia, Castillo y Fuentes (2010) para mayor detalle, por lo menos en tres de los países implicados.

${ }^{7}$ Con base en los documentos más determinantes o preceptivos: ONU, 1948; ONU, 1966a; ONU, $1966 b$. La expresión "derechos humanos" debería restringirse a aquellos que se vinculan con la protección de la vida y contra las agresiones a la integridad (cfr. BEHARES, 2018), a los cuales se suman los derechos civiles, sociales, económicos y culturales, para los cuales se usa más bien la expresión "derechos fundamentales", o simplemente "derechos", criterio que seguimos aquí.

${ }^{8}$ Informan sobre estos procesos Archer (1979) y Gimeno Sacristán (2000). Muestran análisis críticos, ligados a la doctrina de la "desescolarización”, Illich (1985) y Taylor Gatto (2003).

${ }^{9}$ Argentina: un máximo desde 4 hasta 18 años de edad (total: 15 años, la extensión varía según las Provincias) (ARGENTINA, 2006, art. 16). Bolivia: desde 4 hasta 14 años de edad (total: 11 años) (BOLIVIA, 2010, art. 7). Brasil: desde 4 hasta 14 años de edad (total. 11 años) (BRASIL, 1998, art. 4, 1, con modificaciones posteriores). Chile: desde 5 hasta 17 años de edad (total: 13 años) (CHILE, 2009, art. 4). Paraguay: desde 6 hasta 14 años de edad (total: 9 años) (PARAGUAY, 1998, arts. 29 y 32). Uruguay: desde 4 a 14 años de edad (total: 11 años) (URUGUAY, 2008, art. 7).

${ }^{10} \mathrm{E} 1$ republicanismo más típico, con afectación estructural de la cultura política y la organización social, se dio en Uruguay, como lo documentaron investigadores ya a mediados del siglo XX (ZUM FELDE, 1945; REAL DE AZUA, 1964; VANGER, 1963; PENDLE, 1963). No fue tan evidente en Argentina o Chile, y fue francamente problemático en Brasil, Bolivia y Paraguay. La obligatoriedad y universalización gratuita de la enseñanza son señalados como factores determinantes.

${ }^{11}$ Concretamente, las leyes de educación vigentes en los seis países estudiados, definen la educación como un derecho de los ciudadanos y una obligación del Estado (ARGENTINA, 2006, arts. 1, 2, 6; BOLIVIA, 2010, art. 1; CHILE, 2009, arts. 3, 4; PARAGUAY, 1998, arts. 1, 2, 3; URUGUAY, 2008, arts. 1-11). En el 
caso de Brasil la ley incluyó en 1996 un Título III con el título "Do Dereito à Educação e o Dever de Educar" (BRASIL, 1996, Tit. III), que incluía solamente las obligaciones del Estado, pero agregó en 2018 un inciso que legisla explícitamente el derecho a la educación (BRASIL, 1996, art. 3, inc. XIII).

${ }^{12}$ Cinco de los países estudiados hacen mención del derecho a la educación y a la obligatoriedad de la misma en sus Constituciones actualmente vigentes. Brasil (1988) establece el derecho y lo articula con el deber del Estado (art. 205), y fija (art. 208) la obligatoriedad de la enseñanza fundamental. Bolivia (2009) establece el derecho (art. 17), la obligación estatal (arts. 77-78), así como la obligatoriedad para el alumno (art. 81). Chile (2005) fija en conjunto el derecho, la obligatoriedad del Estado y para los alumnos (art. 10). Paraguay (1992) reconoce el derecho (arts. 73-74), establece la obligación del Estado (art. 75) y la obligatoriedad para los alumnos (art. 76). Uruguay (2004) establece el derecho de los padres a educar a sus hijos (art. 41), la obligación del Estado en la enseñanza (art. 71) y la obligatoriedad para los alumnos (art. 70). La Constitución federal argentina (ARGENTINA, 1994) no hace mención a estas cuestiones, que aparecen con sus variaciones en las constituciones de cada Provincia.

${ }^{13}$ Fundamentalmente: ONU, 1948; UNESCO, 1960; ONU, 1966b; ONU, 1989; ONU, 2006.

* Investigador en Ciencias Humanas. Docente Libre del Instituto Superior de Educación Física. Profesor Titular (retirado) de Facultad de Humanidades y Ciencias de la Educación de la Universidad de la República, Montevideo, Uruguay.

\section{Correspondência}

Luis Ernesto Behares - Instituto Superior de Educación Física. Parque Batlle, sin número, 11200 Montevideo, Uruguay.

E-mail:1beharesc@yahoo.com

Recebido em 20 de junho de 2018

Aprovado em 01 de julho de 2018 
